\title{
Notícias diaspóricas: Breve anatomia da comunidade portuguesa em Londres (1808- 1822)
}

\author{
Diasporic News: \\ Brief Anatomy of the Portuguese community in London (1808-1822)
}

\author{
Luís Francisco Munaro \\ Professor do Curso de Jornalismo da UFRR \\ Doutor em História pela UFF \\ luis.munaro@ufrr.br
}

\begin{abstract}
Resumo: Este artigo se debruça sobre a comunidade portuguesa em Londres no primeiro quartel do século XIX. Ela aumentou de tamanho com as perseguições políticas e religiosas movidas pelo Intendente de Polícia Pina Manique e com as invasões francesas em Portugal a partir de 1807. Através de biografias escritas por membros da comunidade, atas de reunião do club português e principalmente jornais, será possível mapear de forma mais precisa o universo de indivíduos lá ambientados, dividindo-os em categorias como "agentes da monarquia", "negociantes", "médicos" ou "jornalistas". A importância destes elementos reside na influência que tiveram na discussão dos rumos da política portuguesa, tomando parte ativa nas Cortes de Lisboa a partir de 1820. Será assim possível identificar suas formas de sobrevivência no exílio, seus interesses comerciais predominantes e suas estratégias para interferir na política do Reino Luso-brasileiro.
\end{abstract}

Palavras-chave: Jornalismo Emigrado em Londres; História Moderna; City of London Tavern; Clubs; Cortes de Lisboa.

\begin{abstract}
This article focuses on the Portuguese community in London in the first quarter of the nineteenth century. Its size increases with the political and religious persecutions by Pina Manique Police Superintendent and with the French invasion from 1807. Through biographies written by community members, the portuguese club meeting minutes and especially newspapers, it is possible to map more precisely the universe of individuals acclimatised there, dividing them into categories such as "agents of the monarchy", "traders", "medical" or "journalists". The importance of these elements lies in the influence they had in the discussion about the future of Portuguese politics, taking an active part in the Lisbon Cortes from 1820. Mapping them more accurately, it is possible to identify their ways of survival in exile, his prevailing business interests and their strategies to interfere in the Luso-Brazilian Kingdom politics.

Keywords: Emigre Journalism in London; Modern history; City of London Tavern; Clubs; Cortes of Lisbon.
\end{abstract}


O objeto deste estudo é a migração portuguesa no início do século XIX desencadeada por conta das pressões da Inquisição portuguesa e das invasões francesas em Portugal. Mais especificamente, este estudo se debruça sobre a comunidade de portugueses fortalecida a partir dessas migrações em direção à cidade de Londres, um dos principais epicentros da resistência dos negociantes e elementos intelectualizados portugueses contra as autoridades políticas que se alternaram em Portugal no primeiro quartel do século XIX. Este estudo teve origem a partir da tese de doutorado "O jornalismo luso-brasileiro em Londres" (2013) que, muito embora tenha se detido sobre a produção jornalística no período, acabou abrindo espaço para a percepção de uma trama de indivíduos portugueses política e socialmente influentes em Londres, independentemente de sua participação direta nos periódicos produzidos pela comunidade. Nesta cidade, eles não apenas usufruíram das liberdades constitucionais inglesas como também tiveram acesso a espaços específicos onde podiam intercambiar ideias, nos moldes de uma esfera pública composta de indivíduos privados. Noutras palavras, os portugueses exilados em Londres se juntaram num público reivindicando acesso à crítica da atividade política, algo inusitado para os padrões de Antigo Regime.

Com a migração da Corte portuguesa para o Rio de Janeiro em 1808, criou-se um campo de expectativas com relação à definição futura do Estado português; em primeiro lugar, no que concerne ao seu alinhamento com Inglaterra ou França e, com o enfraquecimento napoleônico na Península, com relação ao centro do reino e à construção de sua carta constitucional. O estudo de doutorado acima citado abriu a porta para uma indagação relativa ao papel de Londres enquanto capital liberal do século XIX e abrigo da imprensa periódica não apenas portuguesa como também indiana, italiana e espanhola. Só no que concerne às publicações portuguesas que surgiram no período, todas elas sugerindo rumos para a política portuguesa, podemos destacar desde $O$ Mercurio Britânico (1798-1800), passando pelo importante periódico Correio Braziliense (1808-1822) de Hipólito da Costa, além de O Investigador (1811-1819) de Vicente Nolasco, José Abrantes e Castro e José Liberato, O Campeão (1819-21) de José Liberato, O Espelho Moral e Político (1813-1814) e O Português (1814-22) de João Bernardo da Rocha Loureiro e O Padre Amaro (1820-9) de Joaquim de Freitas. A partir do golpe político Vilafrancada em 1823, aconteceu uma nova migração de portugueses para Londres que alimentou outra geração de intelectuais. Além de elementos que já se manifestavam na arena jornalística somaram-se outros como Simões Margiochi, José Silva Carvalho e Almeida Garrett. 
Nosso objeto aqui é especificamente a primeira geração de exilados, investigada a partir dos jornais que constituíram um aspecto fundamental do espaço público em língua portuguesa no início do século XIX. Estes jornais, segundo a interpretação de Valentim Alexandre, refletiram de forma direta a crise do Antigo Regime português, indicando a entrada das ideias liberais em Portugal e o crescimento de setores mais próximos das atividades comerciais (ALEXANDRE, 1993). Quanto ao movimento migratório, o início da formação de uma comunidade de portugueses emigrados remete ainda ao século XVIII, quando viajantes vinculados à Academia de Ciências de Lisboa estabeleceram uma rede de trocas baseadas em epístolas. Como lembra Ângela Domingues, estes intelectuais provenientes "de todos os pontos do Império, exercendo as mais diversas funções e dotados de objetivos diferentes enviavam aos órgãos da administração central sediada em Lisboa informações sobre os mais variados assuntos" (DOMINGUES, 2001).

No século XIX, a situação de instabilidade na Península derivada da ascensão de Napoleão Bonaparte e do aumento das perseguições políticas encabeçadas pelo Intendente de Polícia Pina Manique, resultou na fuga da Condessa de Oyenhausen, D. Leonor Almeida (1802), e de Hipólito da Costa (1805) para Londres, dois dos mais importantes membros da comunidade exilada: a primeira, conhecida pela sua amizade com poetas e indivíduos de tendência liberal; o segundo, um bacharel em leis nascido no Brasil, acusado de pertencimento à Maçonaria. Outros indivíduos, acusados de colaborarem com os franceses, fugiram durante a Setembrizada em 1810 (prisão e deportação de personalidades acusadas de jacobinismo ou pertencimento à Maçonaria), caso de Sebastião José Saldanha, Jácome Ratton, Domingos Vandelli e José Diogo Mascarenhas Neto. Ainda que D. João tenha solicitado aos portugueses recepcionar bem os "visitantes" franceses, as dissidências com autoridades estrangeiras logo começaram a aparecer. Vicente Nolasco, José Liberato, Bernardo da Rocha Loureiro, autores dos jornais Investigador, Campeão e O Português também fugiram em virtude de desacordos políticos com líderes franceses a partir de 1810. Os emigrados portugueses que desembarcaram na Inglaterra foram assim homens que opuseram resistência ideológica às pretensões de Napoleão e não puderam lucrar com a presença francesa em Portugal ou, então, que provocaram desconfiança das autoridades portuguesas por seu pertencimento maçônico e divulgação de ideias liberais.

Através de biografias escritas por membros da comunidade portuguesa emigrada em Londres neste primeiro quartel do século XIX, atas de reunião do club de 
comerciantes portugueses sediado na taverna City of London e principalmente jornais, este artigo buscou mapear de forma mais precisa o universo de indivíduos emigrados, dividindo-os em categorias como "agentes da monarquia" (encarregados de funções políticas no estrangeiro), "negociantes", “médicos” ou “jornalistas”. A importância destes elementos reside na influência que tiveram na discussão dos rumos da política portuguesa, tomando parte ativa nas Cortes de Lisboa a partir de 1820. Será mister destacar a importância dos espaços capazes de garantir o reforço de vínculos de pertencimento político e solidariedade entre os indivíduos em processo de diáspora. Como se verá neste estudo, a taverna City of London, localizada na Bishopsgate Street e as lojas maçônicas podem ter cumprido um papel nuclear no reforço dos laços imaginários dos portugueses em torno de sua nacionalidade, além do espaço óbvio dos papeis impressos como uma narrativa capaz de reunir indivíduos anônimos em torno de interesses comuns (ANDERSON, 1989). É possível destacar, de antemão, que os laços afetivos e intelectuais desta comunidade emigrada eram relativamente coesos, tendo sido central nas suas manifestações jornalísticas a busca para estabelecer sentidos sobre a reconstrução do Reino luso-brasileiro durante e depois do fenômeno napoleônico na Europa (LIMA, 2012). Os instrumentos utilizados para construir esse trânsito de ideias foram, sobretudo, panfletos e jornais impressos na Inglaterra e disseminados no mundo lusófono através da rede de paquetes ingleses. Estes impressos foram os porta-vozes mais importantes dos anseios políticos - de visibilidade - da comunidade exilada e, além disso, insinuaram o vínculo íntimo que havia entre os espaços de sociabilidade frequentados pelos portugueses (tavernas, salões, lojas maçônicas) e as notícias regularmente publicadas nos jornais.

O objetivo deste artigo, antes do destaque às ideias políticas dos atores, está concentrado na tentativa de fornecer um panorama mais claro acerca da dimensão da comunidade portuguesa em Londres, nomeando indivíduos cuja importância foi capital para a sustentação da comunidade e impressão de jornais importantes em todo o mundo lusófono. Para tanto, propomos um breve trabalho de investigação dos nomes e do perfil majoritário dos indivíduos, levando em conta, sobretudo, sua posição social e sua presença na taverna que delimitou o seu campo de participação política e vida social em Londres - a taverna City of London, descrita na primeira parte deste artigo. O mapeamento de 121 nomes foi feito através da leitura dos jornais mencionados na bibliografia deste artigo, sobretudo quando destacavam eventos ou reuniões do Club na taverna, seguidos de listas de participantes, menções feitas na biografia de José Liberato 
e dados historiográficos coletados pelas obras de Mecenas Dourado, Carlos Rizzini e Georges Boisvert (DOURADO, 1957; RIZZINI, 1957; BOISVERT, 1974). Estes dados foram confrontados com o Dicionário Biográfico de Inocêncio Francisco da Silva (1927), que ajudou a verificar a relevância de cada indivíduo mencionado bem como a disponibilidade de material bibliográfico a seu respeito. O estudo, nesse sentido, permitirá perceber outros espaços de trânsito que, embora importantes para a vida comunitária dos portugueses em Londres, aparecerão de forma apenas secundária, como as lojas maçônicas e o salão da Condessa.

\section{O Club dos portugueses em Londres}

A noção que será central para pontuarmos a vivência portuguesa em Londres, aqui concentrada na busca em torno de indivíduos intelectual e politicamente importantes, é a de esfera pública. Esta noção permite intercalar o estudo de espaços específicos e a disseminação de papeis impressos, aspecto fundante da vida política europeia nos séculos XVIII e XIX, sobretudo no que concerne à Inglaterra e à França. De forma abreviada, podemos dizer que a esfera pública

pode ser concebida, antes de mais, como a esfera em que pessoas privadas se juntam enquanto um público; bem cedo, reclamaram que essa esfera pública fosse regulada como se estivesse acima das próprias autoridades públicas; de forma a incluí-las num debate sobre as regras gerais que governam as relações da esfera da troca de bens e de trabalho social basicamente privatizada, mas publicamente relevante (HABERMAS, apud SILVA, 2001: 118).

A esfera pública dos portugueses emigrados, aqui explorada brevemente, indica para a circulação em espaços específicos, considerados liberais, e também publicações periódicas que insinuam uma nova forma de política na qual o rei se submete à crítica, na condição de primeiro cidadão. Os portugueses construíram através desse arcabouço filosófico e político um espaço de circulação de escritos voltados para um público anônimo, com teor desfavorável, de uma forma geral, para o governo português e brasileiro. Estes escritos, conforme engrossou o coro de vozes políticas conflitantes em Portugal, se tornaram gradativamente contrários também à Dinastia de Bragança, 
assumindo, em alguns casos como o de Rocha Loureiro, um tom de forte oposição à figura de D. João VI (BOISVERT, 1982).

O escrito, assim, não paira num universo desconectado da materialidade em que se encontra inscrito, quer dizer, ele depende de espaços onde possa circular e ser lido, onde informações possam ser geradas, sobretudo se tivermos em mente a formação de uma cultura jornalística intimamente dependente das novidades (MUNARO, 2015). No que concerne à comunidade lusófona em Londres, o espaço mais importante, aquele mais mencionado pelos jornais portugueses como capaz de permitir um livre intercâmbio de ideias e trocas de informações dentro de condições liberais, excluídos privilégios e hierarquias de Antigo Regime, foi o Club português sediado na taverna City of London. O Club recebeu várias menções na estrutura dos jornais. Dentre estas, destacamos a explicativa fala de João Bernardo da Rocha Loureiro no seu jornal $O$ Espelho:

Houveram [sic] portugueses que [...] conheceram quanto proveito viria aos negociantes portugueses em Londres e a todo o Portugal, se, à imitação dos ingleses, formassem um club dos seus naturais, que aqui se empregam na honrosa profissão do comércio: a ideia foi posta a obra, de um modo maravilhoso; e assim temos hoje em Londres um club comercial de portugueses, o qual seria utilíssimo, ainda quando só tivesse em vista manter a concórdia e união entre irmãos, filhos da mesma pátria; mas é certo, que o club português deita mais ao longe as suas vistas, e se ocupa de outros objetos de não menor valor e importância, em proveito do comércio e bem da sua pátria ( $O$ Espelho, 10 de setembro de 1813, n. 19: 153-4).

Neste $C l u b$ aconteceram eventos importantes para a organização dos portugueses no estrangeiro e para a construção de grupos políticos que reivindicaram espaço na máquina política portuguesa após a Revolução Liberal do Porto em 1820. Um destes eventos, por exemplo, foi a reunião de juramento de fidelidade às Cortes em Portugal, em que só foi permitido o acesso de elementos luso-brasileiros comprometidos com o avanço das ideias liberais. A tabela que será apresentada adiante torna possível perceber a circulação destes indivíduos, dividindo-os entre aqueles que foram convocados para a reunião liberal e compareceram e aqueles que, pelos motivos os mais variados, faltaram. A reunião, simbolicamente importante para a manifestação de adesão a um novo grupo 
que se instalava no governo português, foi assim descrita por José Liberato no seu jornal O Campeão:

Os Portugueses residentes em Londres, desejando dar uma prova não equívoca de seu patriotismo e lealdade, tem determinado ajuntarem-se na City of London Tavern no dia 4 de Junho de 1821, para votarem um Memorial congratulatório ao Augusto Congresso das Cortes Gerais, Extraordinárias, e Constituintes da Nação Portuguesa; e outro à Majestade do Senhor Rey D. João VI (O Campeão, 1821, V. IV: 248).

Como mencionado, esta taverna ajudou a abrir aos portugueses portas para negociações efetivas com grupos econômicos sediados Londres, lembrando que ela também serviu de sede para o $C l u b$ de negociantes ingleses que buscavam intercambiar com o Brasil: Brazil's trade (The Morning Chronicle, 29 de junho de 1808). Evidentemente, boa parte dos indivíduos que asseguraram ali a sua presença eram negociantes ou indivíduos diretamente dependentes desses mesmos negociantes, já que estes eram responsáveis pela manutenção de subsídios para a impressão de jornais ou para o exercício de outras atividades comunitárias.

Os espaços de sociabilidade mencionados, sobretudo a taverna, não apenas forneceram suporte para as vivências e práticas de grupo em Londres como para atividades de coleta de dados e intercâmbio de pautas e argumentos jornalísticos. Daí a tentativa de apontar alguns dos espaços em que estes indivíduos podem ter circulado e que ajudaram a confeccionar as suas identidades no exterior. Uma vez explicitado este primeiro e mais fundamental espaço e expostos os nomes dos indivíduos, serão brevemente abordados outros espaços fundamentais para a circulação política dos portugueses no estrangeiro: a loja maçônica e o salão da Condessa de Oyenhausen.

\section{Os indivíduos portugueses em Londres}

A tabela a seguir abre espaço para a percepção das disposições políticas e econômicas dos indivíduos portugueses ambientados em Londres, bem como, mais precisamente, de seu posicionamento diante da Revolução Liberal do Porto de 1820 que propunha uma Carta Constitucional Liberal para Portugal. Optou-se por indicar, no caso 
de o dado ser disponível, a descrição e a formação do indivíduo que, em boa parte dos casos, girava em torno da Universidade de Coimbra.

Foram selecionados os indivíduos portugueses ou brasileiros residentes em Londres entre 1808 e 1822, ou seja, entre o traslado da Corte portuguesa para o Brasil e a proclamação da independência brasileira, um ano antes da Vilafrancada. Quando, eventualmente, surgirem nomes de importância que ultrapassam o período de tempo adotado, eles serão registrados com ressalvas, como no caso de Simões Margiochi e José da Silva Carvalho, jornalistas que vão compor a imprensa emigrada a partir das perseguições políticas encabeçadas pelo infante D. Miguel em 1823. Nesse sentido, esta tabela pretende ser também um documento de consulta para os estudiosos da Londres liberal do século XIX ou então para a história de Brasil, Portugal ou Inglaterra.

Sua composição destaca seis elementos que foi possível apurar, na maior parte dos casos de forma imprecisa: o nome do indivíduo apresentado pelos jornais ou pela bibliografia apontada, sua posição social, a menção a que (quando aparecer) o seu nome veio associado, sua presença na supracitada reunião de 1821 de juramento de fidelidade às Cortes liberais de Lisboa, seu ano de nascimento e morte e frequência na Universidade de Coimbra (Idade/Univ.) e os espaços em que sua frequência foi registrada: taverna (Club), Loja Maçônica, White Chapel (embaixada portuguesa), Casa do Negociante José Carvalho, Teatro em Drury Lane e Salão da Condessa Oyenhausen. No que concerne à reunião de 1821, os indivíduos podem ter estado presentes (presente), podem ter sido convocados e não se apresentaram (ausente), ou não tiveram qualquer referência (não consta). A carência de padronização reflete a disposição como os nomes foram apresentados nas atas de reuniões ou nos discursos dos jornais. Daí termos preferido apresentar o nome de forma incompleta a não apresentá-lo de forma alguma.

TABELA 1 - Indivíduos luso-brasileiros que transitaram por Londres entre 1808 e $1822^{1}$

\begin{tabular}{|l|l|l|l|l|l|}
\hline Indivíduo & Posição & Menção & $\begin{array}{l}\text { Reunião } \\
\text { de 1821 }\end{array}$ & $\begin{array}{l}\text { Idade/ } \\
\text { Univ. }\end{array}$ & $\begin{array}{l}\text { Espa- } \\
\text { ços }\end{array}$ \\
\hline $\begin{array}{l}\text { Alexandre Teixeira } \\
\text { Sampaio }\end{array}$ & & & Presente & & $C l u b$ \\
\hline $\begin{array}{l}\text { Ambrósio Joaquim } \\
\text { dos Reis }\end{array}$ & $\begin{array}{l}\text { Agente da da } \\
\text { monarquia }\end{array}$ & $\begin{array}{l}\text { Oficial da secretaria de } \\
\text { Estado }\end{array}$ & $\begin{array}{l}\text { Não } \\
\text { consta }\end{array}$ & & $C l u b$ \\
\hline
\end{tabular}

\footnotetext{
${ }^{1}$ Esta tabela é parte integrante da tese doutoral "O Jornalismo luso-brasileiro em Londres", defendida na Universidade Federal Fluminense em 2013.
} 


\begin{tabular}{|c|c|c|c|c|c|}
\hline $\begin{array}{l}\text { Antonio Cesareo da } \\
\text { Silva }\end{array}$ & & & Presente & & $C l u b$ \\
\hline Antonio da Costa & Negociante & Falido em 1819 & Presente & & $C l u b$ \\
\hline $\begin{array}{l}\text { Antonio da Silva } \\
\text { Povoas }\end{array}$ & Negociante & Importador de vinhos & Presente & & \\
\hline $\begin{array}{l}\text { Antonio Francisco } \\
\text { Abreu }\end{array}$ & Negociante & $\begin{array}{l}\text { Possuiu firma com Jacinto } \\
\text { Dias de Carvalho }\end{array}$ & Presente & & $C l u b$ \\
\hline $\begin{array}{l}\text { Antonio Joaquim } \\
\text { Freire Marreco }\end{array}$ & Negociante & $\begin{array}{l}\text { Secretário honorário do } c l u b \text {, } \\
\text { comerciava vinhos }\end{array}$ & Presente & $\begin{array}{l}1787- \\
1850\end{array}$ & Club \\
\hline $\begin{array}{l}\text { Antonio José } \\
\text { Armando }\end{array}$ & & & Presente & & $C l u b$ \\
\hline $\begin{array}{l}\text { Antonio Julião da } \\
\text { Costa }\end{array}$ & $\begin{array}{ll}\text { Agente } & \mathrm{da} \\
\text { monarquia } & \end{array}$ & $\begin{array}{l}\text { Reunião do Club em 1810, } \\
\text { Consul em Liverpool }\end{array}$ & $\begin{array}{l}\text { Não } \\
\text { consta }\end{array}$ & & \\
\hline Antonio M. Lopes & & & Ausente & & $C l u b$ \\
\hline $\begin{array}{l}\text { Antonio Machado } \\
\text { Braga }\end{array}$ & Negociante & Amigo de Liberato & Presente & & $C l u b$ \\
\hline $\begin{array}{l}\text { Antonio Martins } \\
\text { Pedra }\end{array}$ & Negociante & $\begin{array}{l}\text { Agente do Banco do Brasil, } \\
\text { financiador de Hipólito }\end{array}$ & Presente & & Club \\
\hline Antonio Moniz & & & Presente & & $C l u b$ \\
\hline $\begin{array}{l}\text { Antonio Moreira S. } \\
\text { Paio }\end{array}$ & Negociante & Reunião do Club em 1810 & $\begin{array}{l}\text { Não } \\
\text { consta }\end{array}$ & & $C l u b$ \\
\hline $\begin{array}{l}\text { Antônio Ribeiro } \\
\text { Neves }\end{array}$ & Escrivão & Amigo de Liberato & $\begin{array}{l}\text { Não } \\
\text { consta }\end{array}$ & & \\
\hline $\begin{array}{l}\text { Antonio Teixeira } \\
\text { Sampaio }\end{array}$ & Negociante & $\begin{array}{l}\text { Correspondências do Conde } \\
\text { de Palmela }\end{array}$ & Presente & & $C l u b$ \\
\hline $\begin{array}{l}\text { Antonio Xavier } \\
\text { Castelo Branco }\end{array}$ & & $\begin{array}{l}\text { Abono de viagens para o Rio } \\
\text { de Janeiro em } 1816\end{array}$ & Ausente & & $C l u b$ \\
\hline $\begin{array}{l}\text { Bernardo José de } \\
\text { Abrantes e Castro }\end{array}$ & $\begin{array}{l}\text { Jornalista, } \\
\text { médico }\end{array}$ & O Investigador & $\begin{array}{l}\text { Não } \\
\text { consta }\end{array}$ & $\begin{array}{l}1771- \\
1831 \\
\text { Coimbra }\end{array}$ & $C l u b$ \\
\hline Bruno da Silva & Negociante & $\begin{array}{l}\text { Importava em Londres vinho } \\
\text { português }\end{array}$ & Presente & & $C l u b$ \\
\hline $\begin{array}{l}\text { Candido José Xavier } \\
\text { Dias da Silva }\end{array}$ & $\begin{array}{l}\text { Agente } \quad \mathrm{da} \\
\text { monarquia }\end{array}$ & $\begin{array}{l}\text { Ministro, fundador dos } \\
\text { Annaes, em Londres a partir } \\
\text { de } 1827\end{array}$ & $\begin{array}{l}\text { Não } \\
\text { consta }\end{array}$ & $\begin{array}{l}1769- \\
1833\end{array}$ & Loja \\
\hline $\begin{array}{l}\text { Cipriano Ribeiro } \\
\text { Freire }\end{array}$ & $\begin{array}{ll}\text { Agente } \\
\text { monarquia }\end{array}$ & $\begin{array}{l}\text { Encontrou em Londres } \\
\text { médico para D. Maria }\end{array}$ & $\begin{array}{l}\text { Não } \\
\text { consta }\end{array}$ & $\begin{array}{l}1749- \\
1824 \\
\end{array}$ & $\begin{array}{l}\text { White } \\
\text { Chapel }\end{array}$ \\
\hline $\begin{array}{l}\text { Cristóvão Pedro de } \\
\text { Moraes Sarmento }\end{array}$ & $\begin{array}{l}\text { Agente } \quad \mathrm{da} \\
\text { monarquia }\end{array}$ & $\begin{array}{l}\text { Encarregado dos negócios } \\
\text { portugueses na Inglaterra }\end{array}$ & $\begin{array}{l}\text { Não } \\
\text { consta }\end{array}$ & $\begin{array}{l}1788- \\
1842 \\
\text { Coimbra } \\
\end{array}$ & \\
\hline $\begin{array}{l}\text { Custódio Pereira de } \\
\text { Carvalho }\end{array}$ & Negociante & $\begin{array}{l}\text { Financiou o Campeão, tendo } \\
\text { passado a juventude no Brasil }\end{array}$ & Ausente & $\begin{array}{l}1778- \\
1854\end{array}$ & $C l u b$ \\
\hline Daniel da Cunha & & & Ausente & & $C l u b$ \\
\hline $\begin{array}{l}\text { Daniel Nunes } \\
\text { Ribeiro }\end{array}$ & Negociante & 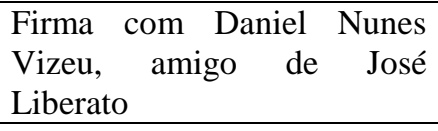 & Presente & & $C l u b$ \\
\hline $\begin{array}{l}\text { Domingos de } \\
\text { Oliveira }\end{array}$ & & & Ausente & & $C l u b$ \\
\hline $\begin{array}{l}\text { Domingos de Sousa } \\
\text { Coutinho }\end{array}$ & Diplomata & & $\begin{array}{l}\text { Não } \\
\text { consta }\end{array}$ & $\begin{array}{l}1760- \\
1833\end{array}$ & $\begin{array}{l}\text { Club/W } \\
\text { hite } \\
\text { Chapel }\end{array}$ \\
\hline $\begin{array}{l}\text { Domingos Ribeiro } \\
\text { de Faria }\end{array}$ & & & Presente & & $C l u b$ \\
\hline $\begin{array}{l}\text { Domingos } \\
\text { Rodrigues de Sá }\end{array}$ & & & Ausente & & $C l u b$ \\
\hline $\begin{array}{l}\text { Faustino da Silva } \\
\text { Ramos }\end{array}$ & & & Ausente & & $C l u b$ \\
\hline $\begin{array}{l}\text { Felisberto Caldeira } \\
\text { Brant }\end{array}$ & Diplomata & $\begin{array}{l}\text { Amigo de Hipólito da Costa, } \\
\text { nomeado por José Bonifácio }\end{array}$ & $\begin{array}{l}\text { Não } \\
\text { consta }\end{array}$ & $\begin{array}{l}1772- \\
1842 \\
\end{array}$ & \\
\hline
\end{tabular}




\begin{tabular}{|c|c|c|c|c|c|}
\hline $\begin{array}{l}\text { Filinto Elisio } \\
\text { (Francisco Manoel }\end{array}$ & Poeta & $\begin{array}{l}\text { Correspondência constante } \\
\text { com membros do } C l u b\end{array}$ & $\begin{array}{l}\text { Não } \\
\text { consta }\end{array}$ & $\begin{array}{l}1734- \\
1819 \\
\end{array}$ & \\
\hline Fortunato Allen & & & Ausente & $\begin{array}{l}1777- \\
1847\end{array}$ & $C l u b$ \\
\hline $\begin{array}{l}\text { Francisco Alpoim e } \\
\text { Meneses }\end{array}$ & Publicista & $\begin{array}{l}\text { Autor do Microscópio de } \\
\text { Verdades }\end{array}$ & $\begin{array}{l}\text { Não } \\
\text { consta }\end{array}$ & & \\
\hline $\begin{array}{l}\text { Francisco Alves de } \\
\text { Carvalho Vianna }\end{array}$ & Negociante & $\begin{array}{l}\text { Firma com Antonio Pedra até } \\
\text { 1817, Sociedade Promotora } \\
\text { da Indústria }\end{array}$ & $\begin{array}{l}\text { Não } \\
\text { consta }\end{array}$ & & \\
\hline $\begin{array}{l}\text { Francisco José } \\
\text { Moreira } \\
\end{array}$ & Negociante & & $\begin{array}{l}\text { Não } \\
\text { consta }\end{array}$ & & \\
\hline $\begin{array}{l}\text { Francisco Lopes da } \\
\text { Cunha }\end{array}$ & Médico & & Ausente & & $C l u b$ \\
\hline $\begin{array}{l}\text { Francisco Nunes } \\
\text { Vizeu }\end{array}$ & Negociante & $\begin{array}{l}\text { Firma com Daniel Nunes } \\
\text { Ribeiro }\end{array}$ & $\begin{array}{l}\text { Não } \\
\text { consta }\end{array}$ & & \\
\hline Francisco Palacios & & & Presente & & $C l u b$ \\
\hline $\begin{array}{l}\text { Francisco Rebelo } \\
\text { Leitão }\end{array}$ & & $\begin{array}{l}\text { Revolução Liberal de } 1820 \text {, } \\
\text { amigo de Rocha Loureiro }\end{array}$ & Ausente & & \\
\hline $\begin{array}{l}\text { Francisco Simões } \\
\text { Margiochi }\end{array}$ & $\begin{array}{l}\text { Jornalista, oficial } \\
\text { da marinha }\end{array}$ & $\begin{array}{l}\text { O Popular, amigo de Bernar } \\
\text { do da Rocha Loureiro, } \\
\text { Londres a partir de } 1826\end{array}$ & $\begin{array}{l}\text { Não } \\
\text { consta }\end{array}$ & $\begin{array}{l}1774- \\
1838 \\
\text { Coimbra }\end{array}$ & \\
\hline $\begin{array}{l}\text { Francisco Solano } \\
\text { Constâncio }\end{array}$ & $\begin{array}{l}\text { Jornalista, } \\
\text { médico, } \\
\text { diplomata }\end{array}$ & & $\begin{array}{l}\text { Não } \\
\text { consta }\end{array}$ & $\begin{array}{l}1777- \\
1846 \\
\text { Edimburg } \\
\text { o }\end{array}$ & \\
\hline $\begin{array}{l}\text { Francisco Teixeira } \\
\text { Sampaio }\end{array}$ & Negociante & $\begin{array}{l}\text { Companhia Geral do Alto- } \\
\text { Douro }\end{array}$ & Presente & & $C l u b$ \\
\hline Guilherme Telles & & & Presente & & $C l u b$ \\
\hline Heliodoro Carneiro & Médico & & Presente & $\begin{array}{l}\text { 1776-??? } \\
\text { Coimbra }\end{array}$ & Salão \\
\hline $\begin{array}{l}\text { Henrique José da } \\
\text { Silva }\end{array}$ & Negociante & $\begin{array}{l}\text { Amigo de Liberato, sócio de } \\
\text { firma com Freire Marreco }\end{array}$ & Presente & $\begin{array}{l}1796- \\
1883\end{array}$ & $C l u b$ \\
\hline Hipólito da Costa & Jornalista & & Presente & $\begin{array}{l}1774- \\
1823 \\
\text { Coimbra }\end{array}$ & $\begin{array}{l}C l u b \\
\text { /loja }\end{array}$ \\
\hline $\begin{array}{l}\text { Honório José } \\
\text { Teixeira }\end{array}$ & Negociante & Reunião do Club em 1810 & $\begin{array}{l}\text { Não } \\
\text { consta }\end{array}$ & & \\
\hline Ignacio Palyart & $\begin{array}{l}\text { Agente } \quad \mathrm{da} \\
\text { monarquia }\end{array}$ & & $\begin{array}{l}\text { Não } \\
\text { consta }\end{array}$ & & $C l u b$ \\
\hline $\begin{array}{l}\text { Jacinto José Dias de } \\
\text { Carvalho }\end{array}$ & & $\begin{array}{l}\text { Reunião do } C l u b \text { em } 1810 \\
\text { como secretário }\end{array}$ & $\begin{array}{l}\text { Não } \\
\text { consta }\end{array}$ & & $C l u b$ \\
\hline $\begin{array}{l}\text { João Antonio } \\
\text { Frutuoso }\end{array}$ & & Reunião do $C l u b$ em 1810 & Presente & & $C l u b$ \\
\hline $\begin{array}{l}\text { João Bernardo da } \\
\text { Rocha Loureiro }\end{array}$ & Jornalista & & Presente & $\begin{array}{l}1778- \\
1853 \\
\text { Coimbra }\end{array}$ & $\begin{array}{l}\text { Club/ } \\
\text { Loja }\end{array}$ \\
\hline João Caetano Rivara & $\begin{array}{l}\text { Gravador de } \\
\text { estampas }\end{array}$ & & Ausente & & $C l u b$ \\
\hline João de Oliveira & $\begin{array}{l}\text { Químico, } \\
\text { negociante }\end{array}$ & & Presente & Londres & $C l u b$ \\
\hline $\begin{array}{l}\text { João de Sá Pereira } \\
\text { Ferreira Soares }\end{array}$ & & $\begin{array}{l}\text { Libelo contra Liberato e } \\
\text { delator de Gomes Freyre }\end{array}$ & $\begin{array}{l}\text { Não } \\
\text { consta }\end{array}$ & Coimbra & \\
\hline João do Valle Porto & & & Ausente & & $C l u b$ \\
\hline $\begin{array}{l}\text { João Domingos } \\
\text { Bomtempo }\end{array}$ & $\begin{array}{l}\text { Pianista, } \\
\text { pedagogo }\end{array}$ & $\begin{array}{l}\text { Retorna a Portugal depois da } \\
\text { queda de Napoleão }\end{array}$ & $\begin{array}{l}\text { Não } \\
\text { consta }\end{array}$ & $\begin{array}{l}1775- \\
1842\end{array}$ & $\begin{array}{l}\text { Drury- } \\
\text { Lane }\end{array}$ \\
\hline João Ferreira Duarte & & Reunião do $C l u b$ em 1810 & $\begin{array}{l}\text { Não } \\
\text { consta } \\
\end{array}$ & & $C l u b$ \\
\hline João Ferreira Pinto & Negociante & $\begin{array}{l}\text { Informa Liberato que D. João } \\
\text { ficaria no Brasil }\end{array}$ & Presente & & $C l u b$ \\
\hline
\end{tabular}




\begin{tabular}{|c|c|c|c|c|c|}
\hline $\begin{array}{l}\text { João Francisco de } \\
\text { Oliveira }\end{array}$ & $\begin{array}{ll}\begin{array}{l}\text { Agente } \\
\text { monarquia }\end{array} & \text { da }\end{array}$ & Amigo de Liberato & $\begin{array}{l}\text { Não } \\
\text { consta }\end{array}$ & & \\
\hline João Jorge Junior & Negociante & Agente do Banco do Brasil & $\begin{array}{l}\text { Não } \\
\text { consta }\end{array}$ & & Club \\
\hline $\begin{array}{l}\text { João Teixeira de } \\
\text { Carvalho }\end{array}$ & Negociante & Amigo de Liberato & Ausente & & Club \\
\hline $\begin{array}{l}\text { Joaquim Ferreira de } \\
\text { Freitas }\end{array}$ & Jornalista & $\begin{array}{l}\text { Redator/fundador do Padre } \\
\text { Amaro }\end{array}$ & $\begin{array}{l}\text { Não } \\
\text { consta }\end{array}$ & & \\
\hline $\begin{array}{l}\text { Joaquim Isidro } \\
\text { Nunes }\end{array}$ & & & Ausente & & Club \\
\hline $\begin{array}{l}\text { Joaquim José } \\
\text { Bandeira }\end{array}$ & & & Presente & & Club \\
\hline $\begin{array}{l}\text { Joaquim José da } \\
\text { Costa e Simas }\end{array}$ & Advogado & $\begin{array}{l}\text { Financiador do Telégrafo de } \\
\text { Loureiro }\end{array}$ & $\begin{array}{l}\text { Não } \\
\text { consta }\end{array}$ & $\begin{array}{l}\text { 1760-??? } \\
\text { Coimbra }\end{array}$ & Loja \\
\hline $\begin{array}{l}\text { Joaquim José da } \\
\text { Silva Lima }\end{array}$ & Negociante & Amigo de Liberato & Presente & & Club \\
\hline $\begin{array}{l}\text { Joaquim José } \\
\text { Vasques Junior }\end{array}$ & $\begin{array}{ll}\text { Agente } & \text { da } \\
\text { monarquia }\end{array}$ & Reunião do Club em 1810 & $\begin{array}{l}\text { Não } \\
\text { consta }\end{array}$ & & Club \\
\hline Joaquim Soares & Negociante & $\begin{array}{l}\text { Ofereceu toda a sua fortuna } \\
\text { para D. Pedro I }\end{array}$ & $\begin{array}{l}\text { Não } \\
\text { consta }\end{array}$ & & Club \\
\hline $\begin{array}{l}\text { José Anselmo } \\
\text { Correia Henriques }\end{array}$ & $\begin{array}{ll}\text { Jornalista } & \mathrm{e} \\
\text { diplomata } & \end{array}$ & $\begin{array}{l}\text { Circulou por Londres, Paris e } \\
\text { Hamburgo. Redigiu os } \\
\text { jornais Argus e Zurrague } \\
\text { (Londres) }\end{array}$ & $\begin{array}{l}\text { Não } \\
\text { consta }\end{array}$ & $\begin{array}{l}1777- \\
1831\end{array}$ & Salão \\
\hline $\begin{array}{l}\text { José Antonio } \\
\text { Gonçalves de } \\
\text { Oliveira }\end{array}$ & & $\begin{array}{l}\text { Cumprimentou D. Miguel em } \\
1827 \text {, esteve presente no } \\
\text { Club em } 1821 \text { e } 1810\end{array}$ & Presente & & Club \\
\hline $\begin{array}{l}\text { José Balbino } \\
\text { Barboza de Araújo }\end{array}$ & Negociante & & $\begin{array}{l}\text { Não } \\
\text { consta }\end{array}$ & & Club \\
\hline $\begin{array}{l}\text { José Caetano de } \\
\text { Bastos }\end{array}$ & Negociante & $\begin{array}{lll}\text { Companhia } & \text { de } & \text { Seguros } \\
\text { Bonança }\end{array}$ & Presente & & Club \\
\hline $\begin{array}{l}\text { José Cesareo da } \\
\text { Silva }\end{array}$ & & & Presente & & Club \\
\hline José Correa da Serra & & Abade Correa da Serra & Ausente & & Club \\
\hline $\begin{array}{l}\text { José da Cunha } \\
\text { Pereira de Neiva }\end{array}$ & $\begin{array}{ll}\begin{array}{l}\text { Agente } \\
\text { monarquia }\end{array} & \text { da }\end{array}$ & & Ausente & & Club \\
\hline $\begin{array}{l}\text { José da Silva } \\
\text { Carvalho }\end{array}$ & Jornalista & $\begin{array}{l}O \text { Popular, revolução } \mathrm{de} \\
1820, \text { Londres em } 1823\end{array}$ & $\begin{array}{l}\text { Não } \\
\text { consta }\end{array}$ & $\begin{array}{l}1782- \\
1856 \\
\text { Coimbra }\end{array}$ & \\
\hline $\begin{array}{l}\text { José de Andrade } \\
\text { Corvo de Camões }\end{array}$ & $\begin{array}{l}\text { Fidalgo da Casa } \\
\text { Real }\end{array}$ & Libelo contra Liberato & $\begin{array}{l}\text { Não } \\
\text { consta }\end{array}$ & 1790-??? & \\
\hline $\begin{array}{l}\text { José de Oliveira } \\
\text { Barreto }\end{array}$ & $\begin{array}{ll}\begin{array}{l}\text { Agente } \\
\text { monarquia }\end{array} & \text { da } \\
\end{array}$ & $\begin{array}{llll}\text { Regente } & \text { nomeado por } & \text { D. } \\
\text { João VI } & & & \end{array}$ & Ausente & & Club \\
\hline $\begin{array}{l}\text { José de Oliveira } \\
\text { Lopo }\end{array}$ & Negociante & Comércio de vinhos & Ausente & & Club \\
\hline $\begin{array}{l}\text { José Diogo } \\
\text { Mascarenhas Neto }\end{array}$ & Magistrado & $\begin{array}{l}\text { Fundador do jornal Annaes } \\
\text { das Sciencias, Artes e Letras } \\
\text { em Paris }\end{array}$ & $\begin{array}{l}\text { Não } \\
\text { consta }\end{array}$ & $\begin{array}{l}1752- \\
1824 \\
\text { Coimbra }\end{array}$ & \\
\hline $\begin{array}{l}\text { José F. Pinto da } \\
\text { Cunha }\end{array}$ & Militar & & $\begin{array}{l}\text { Não } \\
\text { consta }\end{array}$ & & Club \\
\hline José Ferreira Borges & $\begin{array}{l}\text { Magistrado, } \\
\text { deputado }\end{array}$ & $\begin{array}{l}\text { Permanece em Londres entre } \\
1823 \text { e } 1827\end{array}$ & $\begin{array}{l}\text { Não } \\
\text { consta }\end{array}$ & $\begin{array}{l}1786- \\
1838 \\
\text { Coimbra }\end{array}$ & $\begin{array}{l}\text { Sinédri } \\
\mathrm{o}\end{array}$ \\
\hline José Gomes Barreto & Negociante & Dono de escunas & Presente & & Club \\
\hline José Liberato & Jornalista & $\begin{array}{l}\text { Redator dos jornais } O \\
\text { Investigador e } O \text { Campeão }\end{array}$ & Presente & $\begin{array}{l}1772- \\
1855\end{array}$ & $\begin{array}{l}\text { Loja / } \\
\text { Club }\end{array}$ \\
\hline José Luiz de Souza & $\begin{array}{ll}\text { Agente } & \mathrm{da} \\
\text { Monarquia } & \end{array}$ & $\begin{array}{l}\text { Ministro de } \\
\text { Londres }\end{array}$ & $\begin{array}{l}\text { Não } \\
\text { consta }\end{array}$ & & Club \\
\hline José Maria da Silva & & & Ausente & & Club \\
\hline
\end{tabular}




\begin{tabular}{|c|c|c|c|c|c|}
\hline $\begin{array}{l}\text { José Martins } \\
\text { Barroso }\end{array}$ & & Reunião do $C l u b$ em 1810 & $\begin{array}{l}\text { Não } \\
\text { consta }\end{array}$ & & \\
\hline $\begin{array}{l}\text { José Moreira de } \\
\text { Queiroz }\end{array}$ & & & Presente & & Club \\
\hline $\begin{array}{l}\text { José Nunes de } \\
\text { Carvalho }\end{array}$ & Amanuense & $\begin{array}{lll}\text { Legação } & \text { portuguesa } & \text { em } \\
\text { Londres } & & \\
\end{array}$ & Ausente & & $\begin{array}{l}\text { José } \\
\text { Carvalh } \\
\text { o }\end{array}$ \\
\hline José Pinheiro Viseu & & & Presente & & Club \\
\hline José Pires Ferreira & & & Ausente & & Club \\
\hline $\begin{array}{l}\text { José Sebastião de } \\
\text { França }\end{array}$ & Negociante & Foi presidente do $C l u b$ & $\begin{array}{l}\text { Não } \\
\text { consta }\end{array}$ & & Club \\
\hline José Vanzeller & Negociante & $\begin{array}{lll}\begin{array}{l}\text { Consignatário } \\
\text { ingleses }\end{array} & \text { de } & \text { navios } \\
\end{array}$ & Presente & & Club \\
\hline $\begin{array}{l}\text { José Vitorino } \\
\text { Barreto Feio }\end{array}$ & Militar & $\begin{array}{l}\text { Revolução Liberal, amigo de } \\
\text { Loureiro }\end{array}$ & $\begin{array}{l}\text { Não } \\
\text { consta }\end{array}$ & & Loja \\
\hline $\begin{array}{l}\text { José Xavier de } \\
\text { Bastos Manoel }\end{array}$ & & & Presente & & Club \\
\hline $\begin{array}{l}\text { Joseph Timothy } \\
\text { Haydn }\end{array}$ & Jornalista & Permanece em Dublin & $\begin{array}{l}\text { Não } \\
\text { consta }\end{array}$ & Dublin & \\
\hline L. F. de Carvalho & Negociante & Amigo de Joaquim de Freitas & $\begin{array}{l}\text { Não } \\
\text { consta }\end{array}$ & & $\begin{array}{l}\text { José } \\
\text { Carvalh } \\
\text { o }\end{array}$ \\
\hline Lourenço de Lima & $\begin{array}{ll}\text { Agente } & \text { da } \\
\text { Monarquia } & \end{array}$ & Ministro & Ausente & $\begin{array}{l}1767- \\
1839\end{array}$ & Club \\
\hline $\begin{array}{l}\text { Lourenço Rodrigues } \\
\text { de Sá }\end{array}$ & & & Ausente & & Club \\
\hline Luís Augusto May & Jornalista & $\begin{array}{l}\text { Secretaria da Legação } \\
\text { Estrangeira em Londres }\end{array}$ & $\begin{array}{l}\text { Não } \\
\text { consta }\end{array}$ & $\begin{array}{l}1782- \\
1850\end{array}$ & Salão \\
\hline Luís Lacomba & Músico ? & & Ausente & & Club \\
\hline $\begin{array}{l}\text { Manoel Antonio de } \\
\text { Freitas }\end{array}$ & Negociante & $\begin{array}{l}\text { Parceiro de Antonio da Costa } \\
\text { falido em } 1829\end{array}$ & Presente & & \\
\hline $\begin{array}{l}\text { Manoel Fernandes } \\
\text { Alves }\end{array}$ & & Reunião do $C l u b$ em 1810 & $\begin{array}{l}\text { Não } \\
\text { consta }\end{array}$ & & Club \\
\hline $\begin{array}{l}\text { Manoel Joaquim } \\
\text { Soares }\end{array}$ & Negociante & Amigo de Liberato & $\begin{array}{l}\text { Não } \\
\text { consta }\end{array}$ & & \\
\hline $\begin{array}{l}\text { Manoel José da } \\
\text { Gama Machado }\end{array}$ & & & Ausente & & Club \\
\hline $\begin{array}{l}\text { Manoel José } \\
\text { Ferreira Camelo }\end{array}$ & Negociante & Companhia de Tabacos & Presente & & Club \\
\hline $\begin{array}{l}\text { Manoel José Gomes } \\
\text { da Costa }\end{array}$ & & & Ausente & & Club \\
\hline $\begin{array}{l}\text { Manoel Ribeiro } \\
\text { Guimarães }\end{array}$ & & Tesoureiro do Club em 1810 & $\begin{array}{l}\text { Não } \\
\text { consta }\end{array}$ & & Club \\
\hline $\begin{array}{l}\text { Manuel Inácio } \\
\text { Martins Pamplona }\end{array}$ & $\begin{array}{l}\text { Militar, } \\
\text { diplomata }\end{array}$ & $\begin{array}{lll}\text { Inimigo } & \text { de } & \text { Heliodoro } \\
\text { Carneiro } & & \\
\end{array}$ & $\begin{array}{l}\text { Não } \\
\text { consta }\end{array}$ & $\begin{array}{l}1760- \\
1832\end{array}$ & \\
\hline $\begin{array}{l}\text { Miguel Caetano de } \\
\text { Castro }\end{array}$ & $\begin{array}{l}\text { Jornalista, } \\
\text { médico }\end{array}$ & $\begin{array}{l}\text { Membro do Royal College of } \\
\text { Phisicians }\end{array}$ & $\begin{array}{l}\text { Não } \\
\text { consta }\end{array}$ & $\begin{array}{l}\text { Edimburg } \\
\mathrm{o}\end{array}$ & $\begin{array}{l}\text { White } \\
\text { Chapel/ } \\
\text { Loja }\end{array}$ \\
\hline $\begin{array}{l}\text { Miguel Dias de } \\
\text { Faria }\end{array}$ & Negociante & & $\begin{array}{l}\text { Não } \\
\text { consta }\end{array}$ & & Club \\
\hline $\begin{array}{l}\text { Nicoláo José Vaz } \\
\text { Salgado }\end{array}$ & & & Presente & & Club \\
\hline Pato Moniz & Jornalista & Autor do Telégrafo & $\begin{array}{l}\text { Não } \\
\text { consta }\end{array}$ & & \\
\hline Pedro Brown & Médico & & Presente & & Club \\
\hline $\begin{array}{l}\text { Pedro de Sousa } \\
\text { Holstein }\end{array}$ & Diplomata & Conde de Palmela & $\begin{array}{l}\text { Não } \\
\text { consta }\end{array}$ & & $\begin{array}{l}\text { White } \\
\text { Chapel }\end{array}$ \\
\hline Pedro do Couto & & & Presente & & Club \\
\hline Pedro Pinto de & Militar & Libelo contra Liberato e & Não & & \\
\hline
\end{tabular}




\begin{tabular}{|l|l|l|l|l|l|}
\hline Moraes Sarmento & & delator de Gomes Freire & consta & & \\
\hline $\begin{array}{l}\text { Rafael da Cruz } \\
\text { Guerreiro }\end{array}$ & $\begin{array}{l}\text { Agente da } \\
\text { Monarquia }\end{array}$ & $\begin{array}{l}\text { Legação Portuguesa em } \\
\text { Londres }\end{array}$ & Ausente & & $\begin{array}{l}\text { White } \\
\text { Chapel }\end{array}$ \\
\hline $\begin{array}{l}\text { Ricardo Lino da } \\
\text { Silva }\end{array}$ & & Presente & & Club \\
\hline Vicente Nolasco & $\begin{array}{l}\text { Médico, } \\
\text { jornalista }\end{array}$ & Redator de O Investigador & & Coimbra & $\begin{array}{l}\text { Club/ } \\
\text { Loja }\end{array}$ \\
\hline
\end{tabular}

Apesar das nítidas lacunas nos dados sobre as funções desempenhadas pelos indivíduos, suas idades e formação, os indícios de funcionamento da comunidade emigrada que ela permite perceber são bastante esclarecedores. Em um primeiro momento, a tabela deixa notar que a presença de indivíduos autonomeados jornalistas é significativa. Daí, inclusive, o título deste artigo ser "notícias diaspóricas": o barulho feito pela comunidade exilada deriva desta grande disponibilidade de intelectuais que se converteram em propagandistas da causa liberal. Se levarmos em conta que, dos 121 indivíduos arrolados, 13 deles chegaram a exercer o ofício jornalístico de forma regular e mesmo depender dele para sobreviver numa altura ou noutra de suas vidas, lidamos com uma porcentagem de mais de um jornalista para cada grupo de 10 indivíduos. Nem todos eles, é claro, dependeram da mesma forma que Hipólito da Costa, Joaquim de Freitas, José Liberato, João Bernardo da Rocha Loureiro e Joseph Timothy Haydn, do jornalismo para sobreviver. Estes não apenas escreveram em jornais regularmente como dependeram do exercício jornalístico como forma principal de sustento econômico no estrangeiro, ao contrário daqueles que estiveram em redações de jornais de forma transitória.

Alguns dos jornalistas manifestaram um trânsito ambíguo entre espaços caracterizados pela presença de agentes monárquicos (White Chapel, onde estava localizada a Embaixada Portuguesa em Londres) e espaços liberais (Club de negociantes). Dentre eles, José Liberato, defensor da Revolução Liberal, frequentou a Casa de D. Domingos de Sousa Coutinho e do Conde de Palmela na White Chapel em Londres, elementos considerados alinhados ao absolutismo monárquico. O Embaixador português em Londres D. Domingos de Sousa Coutinho, irmão do Ministro do rei D. Rodrigo de Sousa Coutinho, chegou a ser ele mesmo frequentador da taverna City of London (seu nome está em chamadas de membros de 1810) até que os ataques dirigidos contra ele por negociantes e jornalistas começaram a se tornar mais frequentes. Nesse sentido, Hipólito da Costa descreveu em 1815 o desgaste sofrido pelo Club com a permanência nele de D. Domingos, o Conde de Funchal: 
Outro estabelecimento de que se lembraram os portugueses em Inglaterra foi um Club em Londres, organizado segundo as formas dos Clubs ingleses. Este ajuntamento prometia grandes vantagens; porém fosse ignorância, fosse maldade de alguns poucos de seus membros, admitiu-se o Conde de Funchal [D. Domingos], que com a sua infeliz qualidade de estragar tudo em que se mete, em pouco tempo reduziu uma associação que prometia muitos dias de felicidade e harmonia a seus membros, a uma fonte de intrigas e rixas. [...] Estava o Club quase deserto, quando a feliz saída de S. Exa da Inglaterra, removendo a fonte de discórdia melhorou logo o estabelecimento; e se diz; que muitos portugueses dos de melhor nome e graduação deram o seu nome para membros do Club, logo que o Conde foi tirado do lugar de Embaixador em Londres (Correio Braziliense, 1815, Vol. XV: 752-3).

Entre os indivíduos convidados para fazer o juramento de fidelidade às Cortes em 1821 temos uma grande parcela vinculada às atividades comerciais. Quando apareceram dentre os convocados agentes monárquicos como D. Lourenço de Lima, Rafael da Cruz Guerreiro, José de Oliveira Barreto, José da Cunha Pereira de Neiva e o abade Correia da Serra, eles não se apresentaram. Evidentemente, para indivíduos diretamente vinculados ao aparelho monárquico, representava uma postura comprometedora apresentar-se a uma reunião de juramento de fidelidade que promovia uma severa revisão no poder conferido ao monarca bragantino. É até mesmo possível especular que, na medida em que a presença na taverna exigia certa reciprocidade entre os seus membros na hora de estabelecer filiações e relações econômicas e políticas, os agentes monárquicos vinculados a certo modo de aparição pública considerado ultrapassado se viam coagidos a não participar ou simplesmente se viam inadequados aos trânsitos de poder e figuração do local.

Ainda como demonstrado pela tabela, dentre os 42 indivíduos que estavam presentes na reunião de juramento às Cortes em 1821 e cujas funções foi possível mapear de forma mais ou menos precisa, ao menos 18 eram negociantes, 3 médicos, 3 jornalistas e nenhum era agente monárquico. Dentre o total de 32 indivíduos ausentes, são ao menos 3 negociantes, 1 médico, 1 músico e 5 agentes monárquicos. Ao passo, portanto, que nenhum agente monárquico assinou o juramento de fidelidade às Cortes de Lisboa, eles respondiam por $15 \%$ daqueles cujos nomes constavam na lista de ausentes. A dificuldade, assim, de se apresentar a uma reunião de juramento às Cortes 
Liberais estando diretamente vinculado ao aparelho do Antigo Regime parece evidente. Os agentes da monarquia recusaram a sua presença e ajudaram a mostrar que não tinham muita intimidade com o espaço do Club.

Por outro lado, parece também evidente a dificuldade de atacar os jornalistas bem ambientados no Club e subsidiados por um número mais ou menos substantivo de negociantes. Dentre os 74 indivíduos convocados para o juramento, pelo menos 22 podiam ser identificados como negociantes. Na amostragem total, esse número sobe para pelo menos 34 indivíduos. Além desse crescente pano de fundo que pode ter funcionado como sustentáculo econômico da atividade dos jornalistas portugueses em Londres, é possível perceber outras parcerias importantes disponíveis no mundo inglês.

\section{Outros espaços de trânsito em Londres}

A tabela menciona, de relance, outro espaço de circulação: a loja maçônica. Havia uma harmonia de propósitos entre o exercício do jornalismo e a maçonaria, ambas adversárias, em seus conceitos e práticas, da arquitetura de poder do Antigo Regime. Somados aos seus pressupostos liberais e de rejeição às hierarquias "mundanas", Alexandre Mansur Barata sugere que, para os indivíduos de tendências liberais, estava nítida a "percepção da maçonaria como um espaço de convívio e mobilidade sociais” (BARATA, 2006: 100). Assim, apesar do seu secretismo, ela absorvia setores sociais autoproclamados liberais e permitia uma interação mais flexível com relação às coerções nobilitárias ainda muito presentes em Portugal.

No caso de um Hipólito da Costa, estudante de leis que se celebrizou pelos seus diários da viagem à Filadélfia, as lojas maçônicas abriram espaço para a sua amizade com o Duque de Sussex, filho do rei George III, tornando-o politicamente influente. Não fosse essa amizade, teria sido bastante difícil para o patriarca da imprensa lusófona manter-se na ilha e construir um projeto tão longevo quanto o Correio Braziliense. Outro caso que indispôs as autoridades portuguesas, o de José Anselmo Correia Henriques, mereceu a extradição exemplar: além de não possuir qualquer tipo de cidadania inglesa, como tinha Hipólito (DOURADO, 1957), Anselmo Correia colocouse em oposição aberta contra a Maçonaria, escrevendo em 1816 uma longa carta para D. João explicando os motivos por que aquela "associação execrável" deveria ser extinta. Parece ter sido mais difícil a vida de indivíduos não maçons. Pode-se mesmo especular 
que a presença em lojas era uma estratégia preliminar para a fixação e sobrevivência política na ilha.

Não por acaso, todos os redatores de jornais arrolados na tabela participaram, numa altura ou noutra, de reuniões em lojas maçônicas. Como exemplo, Hipólito da Costa foi preso pela Inquisição justamente em virtude disso, enquanto Vicente Nolasco foi perseguido a partir de declarações pouco discretas feitas durante uma reunião com franceses numa loja maçônica portuguesa (MACHADO, 1998: 477). Bernardo José Abrantes e Castro, o Dr. Castro, também se vinculou à Maçonaria e foi chamado pela Intendência de Polícia portuguesa a prestar esclarecimentos por conta de sua vinculação (MACHADO, 1998: 478). Os traços deixados pela Maçonaria na cultura portuguesa na Ilha ainda merecem um estudo mais aprofundado, sobretudo no que diz respeito ao trânsito internacional de indivíduos, para além dos limites nacionais em que elas têm sido comumente estudadas.

Outro dos indicadores de sociabilidade dos portugueses na ilha, apontado na tabela, é o círculo de participantes do salão da condessa de Oyenhausen, acessível graças aos vários anos de estudos documentais de Mecenas Dourado. A Condessa migrou para Londres em 1802, onde passou a reunir outros elementos emigrados, lembrando os tempos dourados do seu Salão em Benfica (GONÇALVES, 2002: 193). Entre os elementos mencionados por Dourado encontram-se Vicente Nolasco da Cunha, José Anselmo Correia Henriques, Heliodoro Carneiro e Luís Augusto May (DOURADO, 1957: 177). Contudo, o papel desempenhado pelo salão, no qual ainda resistia um apego às hierarquias mundanas, foi sem dúvida muito menor que aquele desempenhado pela taverna e pelas lojas maçônicas, estas sim mais capazes de permitir um verdadeiro trânsito entre elementos ingleses e portugueses.

Ainda no que concerne aos espaços de sociabilização cabe mencionar a função fundamental do pano de fundo compartilhado pelos jornalistas fruto do estudo em comum na Universidade de Coimbra. A centralidade dessa Universidade para o intelecto luso-brasileiro tem sido bastante trabalhada, de forma que é possível perceber suficientemente bem o seu papel na condução dos projetos de nacionalidade ou reforma política no Brasil e em Portugal no início do Oitocentos. Dentre os jornalistas emigrados, cabe apenas citar, a título de exemplo, o caso longevo de Francisco Simões Margiochi, que deixa ver a longa formação intelectual e política aberta pela Universidade. Formado em 1798, foi responsável pelo jornal O Popular juntamente com José da Silva Carvalho a partir de 1824, ajudando, antes disso, a organizar a conspiração 
do Sinédrio em 1817 em conjunto com Ferreira Borges e Fernandes Tomás (SILVA, tomo IX: 60). Tanto Margiochi quanto os responsáveis pelo jornal O Investigador, além de Rocha Loureiro, Hipólito da Costa e D. Domingos, tinham em comum o ensino Coimbrão: "a Universidade de Coimbra reformada proporcionava a cada um uma bagagem cognitiva completamente nova [...] que acabou por dotar os seus alunos do espírito crítico necessário à implantação de uma nova cultura que coava o conhecimento adquirido e a adquirir através do funil da legitimação racional" (MACHADO, 1997: 479).

Houve, portanto, antes mesmo da diáspora portuguesa de 1807, uma vivência em comum e também um cruzamento de experiências intelectuais que permitiram a cada um dos autores de jornais compartilhar determinada "bagagem cognitiva". O estreito círculo formado a partir da vivência na Universidade, da qual apenas se exclui José Liberato, membro da Academia de Ciências de Lisboa, se encaixa perfeitamente nas conclusões subsequentes.

\section{Considerações finais}

O percurso dos três principais jornalistas lusófonos em Londres, Hipólito da Costa, Rocha Loureiro e José Liberato, parece ter tido uma teia de financiamentos e interdependências relativamente estável, lembrando do vínculo de José Liberato com Abrantes e Castro e Custódio Pereira, de Hipólito da Costa com o Duque de Sussex e Antonio Martins Pedra, e de Rocha Loureiro com o próprio Hipólito e com Joaquim da Costa Simas. Há, nas suas biografias, vários indícios que permitem particularizar essas relações de afinidade intelectual que teriam possibilitado um trânsito relativamente estável na ilha - não confortável, como o comprovam as biografias de José Liberato e do espanhol Joseph White, já que os escritores sempre alegavam viver em situação de penúria econômica (LIBERATO, 1855; WHITE, 1830).

As dificuldades de relacionamento entre os três começaram a crescer a partir da derrocada de Napoleão na Europa e da busca pela proposição de reformas políticas para Brasil e Portugal. Nas trocas de farpas entre eles, José Liberato era associado ao "jornal da Embaixada", Hipólito da Costa ao comércio de escravos brasileiro e Rocha Loureiro ao governo espanhol. Em 1821 aconteceu, por ocasião do juramento de fidelidade às Cortes, um cessar fogo entre os três e, simbolicamente, um abraço entre irmãos. Nesse 
mesmo encontro, como testemunhou José Liberato (1855), este recebeu uma caixa de ouro contendo o nome de vários negociantes portugueses, em virtude de seus préstimos à nação portuguesa. $\mathrm{O}$ cessar fogo não duraria muito tempo: cada um já havia escolhido uma postura específica no contexto de desagregação do Antigo Regime Português e diante da autonomia política do Brasil.

Por um breve período de tempo, entre a Revolução Liberal e o início da VilaFrancada em 1823, Londres deixou de cumprir um papel decisivo no sentido de abrigar a palavra impressa portuguesa, já que Portugal teoricamente teria criado condições de fomentar o seu próprio comércio livreiro. Seu legado, contudo, já havia sido dado. As possibilidades de pensamento externas à censura no reino permitiram aos exilados oferecer uma contribuição intelectual bastante significativa, avant la lettre em alguns casos, como no que diz respeito à condenação do tráfico de escravos, à denúncia da incompetência do rei ou à defesa da permanência da corte em solo brasileiro. Todas essas ideias, contudo, estão bastante vinculadas aos indivíduos que funcionaram como patronos dos jornais, demonstrando a importância dos negociantes exilados para a virada política de 1820 e para o financiamento de uma oposição escrita à arquitetura de poder do Antigo Regime português.

\section{Fontes}

Correio Braziliense ou Armazém Literário (1808-1822). Hipólito José da Costa. Londres: W. Lewis.

LIBERATO, José (1855). Memórias da vida. Lisboa.

O Campeão portuguez ou amigo do rei e do povo (1819-1821). José Liberato Freire de Carvalho. Londres.

O Espelho Politico e Moral (1813-1814). João Bernardo da Rocha Loureiro. Londres.

O Investigador Portuguez em Inglaterra ou Jornal Literário, Politico, etc. (1811-1819). Bernardo José de Abrantes e Castro, Vicente Pedro Nolasco da Cunha, Miguel Caetano de Castro e José Liberato Freire de Carvalho. Londres.

O Portuguez ou Mercurio Politico, commercial e litterario (1814-1822). João Bernardo da Rocha Loureiro. Londres.

O Padre Amaro ou Sovela Politica e Literaria (1820-1828). Joaquim Ferreira de Freitas. Londres.

SILVA, Inocêncio Francisco (1927). Dicionário Biográfico. Coimbra: Imprensa da Universidade.

The Morning Chronicle (1808). Londres.

WHITE, José Maria Blanco ([1830] 1975) [1775-1841]. Autobiografia. Sevilha: Universidad. Disponível em http://www.cervantesvirtual.com/obra/autobiografiade-blanco-white--0/. Acesso abr. 2016. 


\section{Referências bibliográficas}

ALEXANDRE, Valentim (1993). Os sentidos do Império. Porto: Edições Afrontamento, 1993.

ALVES, José Augusto dos Santos (1987). O Portuguez e o discurso de saber/poder. Cultura - Revista de História e Teoria das ideias. Universidade Nova de Lisboa/Centro de História da Cultura, v. 6, pp. 699-724.

ALVES, José Augusto dos Santos (1988). Ideologia e política na imprensa do exílio. Lisboa: Instituto Nacional de Investigação Científica.

ANDERSON, Benedict (1989). Nação e Consciência Nacional. São Paulo: Ática.

BARATA, Alexandre (2006). Maçonaria, Sociabilidade Ilustrada e Independência do Brasil (1790-1822). São Paulo: Annablume.

BOISVERT, Georges (1982). Um pionnier de la propagande liberale au Portugal. João Bernardo da Rocha Loureiro (1778-1853). Paris: Fundação Calouste Gulbekian..

DOMINGUES, Angela (2006). Notícias do Brasil colonial - a imprensa científica e política a serviço das elites (Portugal, Brasil e Inglaterra). In: Varia Historia, v. 22, n. 35, Belo Horizonte, pp. 150-174.

DOURADO, Mecenas (1957). Hipólito da Costa e o Correio Braziliense. Rio de Janeiro: Bibliex.

GONÇALVES, Adelto (2002). Bocage e a Maçonaria. Revista Cultura - história e teoria das ideias, n. 14, pp. 187-202.

LIMA, Péricles (2012). A Corte no Brasil e os periódicos portugueses 1808-1821. Tese de Doutorado em História apresentada na Universidade Nova de Lisboa. Lisboa.

MACHADO, Adelaide Maria Muralha Vieira (1998). O Investigador Português em Inglaterra, nos primeiros anos de publicação (1811-1813) - Uma apresentação. Cultura - Revista de História e teoria das ideias. CASTRO, Zília Osório e PEREIRA, Sara Marques. Vol X, pp. 473-491.

MUNARO, Luís Francisco (2015). A articulação de jornalismo e espaços públicos na Ilustração Inglesa. Revista Compolitica, Salvador. (2013). O jornalismo luso-brasileiro em Londres. Tese de doutorado em História apresentada à Universidade Federal Fluminense. Niterói.

OLIVEIRA, José Carlos de (1998). Os periódicos portugueses de Inglaterra e a Cultura Científica Brasileira (1808-1821). Revista da SBHC, n.19, pp. 31-62.

RIZZINI, Carlos (1957). Hipólito da Costa e o Correio Braziliense. São Paulo: Companhia Editora Nacional.

SILVA, Filipe Carreira (2001). Habermas e a esfera pública: reconstruindo a história de uma ideia. Plataforma democrática. Disponível em: $<$ http://www.plataformademocratica.org/

Publicacoes/Publicacao_9362_em_06_06_2011_12_34_08.pdf>. Acesso em: Abril 2016.

Artigo recebido em 25 de junho de 2015.

Aprovado em 27 de maio de 2016.

DOI: $10.12957 /$ intellectus.2016.23843 